\title{
Evidence for a Novel Mechanism of Binding and Release of Stimuli in the Primate Taste Bud
}

\author{
Albert I. Farbman' ${ }^{1}$ and Göran Hellekant ${ }^{2}$ \\ 'Department of Neurobiology and Physiology, Northwestern University, Evanston, Illinois 60208, and 2Department of \\ Veterinary Science, University of Wisconsin, Madison, Wisconsin 53706
}

In previous work, we showed that thaumatin, an intensely sweet protein, binds to certain formed elements in taste pores of Rhesus monkey foliate papillae, namely, microvilli and small vesicles shed from microvilli, in addition to amorphous secretions (Farbman et al., 1987). We suggested that the taste bud responds to a thaumatin stimulus by shedding the small vesicles containing fragments of microvillar membrane bearing the stimulus-binding site complex. To examine this hypothesis further, we used electron microscopy to examine taste pores of both vallate and foliate papillae from Rhesus monkeys before or after stimulation with thaumatin or sucrose. We also recorded the neural activity from the glossopharyngeal nerve during stimulation with thaumatin, sucrose, citric acid, and $\mathrm{NaCl}$. The results indicate (1) with no stimulation, vesicles are found in pores of foliate papilla taste buds much more frequently than in pores of vallate papilla buds, (2) in both types of papillae, stimulation with sucrose has no apparent effect on the number of pores containing vesicles, (3) stimulation with thaumatin elicits release of vesicles into pores of both foliate and vallate buds, (4) repeated stimulation of taste buds with thaumatin results in a declining neural response, not seen after repeated stimulation with sucrose, citric acid, or $\mathrm{NaCl}$, and (5) stimulation with thaumatin suppresses the neural response to sucrose, but the reverse does not occur. The combined morphological and physiological data support our original hypothesis that, in response to thaumatin stimulation, binding sites on taste microvillar membranes may be shed as a stimulus-receptor complex into the pore. Alternatively, the binding sites may in some way be altered by the shedding of part of the membrane. The data suggest further that the binding site for sucrose may be close to that for thaumatin because it too is lost or altered after thaumatin stimulation. The reduced neural response after repeated thaumatin stimulation indicates that cells may have suffered a net loss of functional receptors or at least a loss in functional capacity of the receptors. The data indicate that the cellular mechanism for handling the protein sweetener, thaumatin, is strikingly different from the adsorption-desorption response to saccharide sweeteners.

\footnotetext{
Received Aug. 12, 1988; revised Mar. 31, 1989; accepted Apr. 6, 1989.

We thank Todd M. Clark for his technical assistance.

This work was supported by NIH grant NS17021. We wish to thank Drs. Henk Van der Wel, Bert Menco, and Ralph M. Albrecht for their advice and help in these studies.

Correspondence should be addressed to Dr. Albert I. Farbman, Department of Neurobiology and Physiology, Northwestern University, 2153 Sheridan Road, Evanston, IL 60208-3520.

Copyright (C) 1989 Society for Neuroscience $0270-6474 / 89 / 103522-07 \$ 02.00 / 0$
}

Thaumatin is an intensely sweet-tasting protein, isolated from the fruit of a west African plant, Thaumatococcus danielli (Van der Wel and Loewe, 1972). This protein tastes sweet in solution at a concentration as low as $10^{-7}$ to $10^{-8} \mathrm{M}$, several orders of magnitude less than the threshold for sucrose taste. Thaumatin consists of a single polypeptide chain of 207 amino acids, has a molecular weight of 22,209, and a pI of 12 (Iyengar et al., 1979). The amino acid sequence (Iyengar et al., 1979) and 3-dimensional structure (De Vos et al., 1985) are known.

The taste of thaumatin and that of another sweet protein, monellin, are detected by Old World (Catarrhine) monkeys, apes, and humans but not by most other mammals, including dogs, hamsters, prosimians, and New World (Platyrrhine) monkeys (Brouwer et al., 1973; Hellekant, 1976; Glaser et al., 1978). These data, from neurophysiological and behavioral studies, suggest that the receptor for these sweet proteins is expressed only in the so-called higher primates, whercas the receptors for carbohydrate sweeteners are more universal; that is, they are present in virtually all terrestrial vertebrates, as well as many invertebrates.

In addition to the studies showing phylogenetic differences in sweet taste reception, there is a growing body of evidence suggesting the existence of multiple receptor types for sweetness (Hellekant, 1975; Faurion et al., 1980; Crosby and DuBois, 1981; Jakinovich, 1982; Yamada et al., 1983; Van der Wel et al., 1987; Jakinovich and Sugarman, 1988). In brief, this is based largely on the striking variation in molecular structure of sweet compounds (cf. sucrose, saccharin, lead acetate, and thaumatin) and differences in response to substances of similar structure, such as glucopyranose and fructofuranose (Ninomiya et al., 1984; Beidler and Tonosaka, 1985).

Certain properties of thaumatin make it useful for studies on the mechanism of sweet taste. For example, the sweet taste of thaumatin lingers longer than that of saccharide sweeteners (Brouwer et al., 1983), and its sweetness depends on its binding to membranes (Van der Wel and Bel, 1976). The thaumatin molecule can be conjugated with markers, e.g., colloidal gold, and still maintain its sweetness. These properties enabled us to show that, when colloidal gold-labeled thaumatin is applied to the taste bud-bearing foliate papillae of Rhesus monkeys, gold particles were detected with electron microscopy largely in the taste pores and not on surrounding tongue surfaces (Farbman et al., 1987). They were bound occasionally to the tips of some microvilli but more frequently to small, 50-100 nm diameter, membrane bounded vesicles and to amorphous secreted substances. The small vesicles, constituted of membrane and cytoplasm presumably originating from the cell apices, were thought to be shed into the pore from the tips of taste bud cell microvilli 
as an apocrine secretion. We proposed that the shedding of these vesicles may be an important means by which taste bud cells rid themselves of certain stimulus-receptor complexes, particularly when the stimulus is a large or highly charged molecule, such as thaumatin (Farbman et al., 1987).

In the present study, we examine this hypothesis further. If the vesicles in the pore represent the means by which cells shed thaumatin receptors bound to the stimulus, one can make certain predictions. First, stimulation by thaumatin might induce more apocrine secretion than, e.g., stimulation by another sweet molecule, such as sucrose. Second, after repeated thaumatin stimulation, there would be more secretion, and, therefore, fewer functional thaumatin-binding sites would remain on the taste bud cell. This should result in a reduced neural response that could be measured physiologically. The results have borne out these predictions and are consistent with our hypothesis that thaumatin may be shed, together with its binding site, into the pore. Thus, its behavior is very different from that of sweet molecules, like hexose sugars, that are bound weakly to their receptors by adsorption and released by desorption (Beidler, 1954).

\section{Materials and Methods}

Morphology. Rhesus monkeys were anesthetized with ketamine $(20 \mathrm{mg} /$ $\mathrm{kg}$ body weight) and given glycopyrrolate $(0.04 \mathrm{mg})$ to inhibit salivary secretion. In earlier experiments, we found that secretion of saliva interfered with our results because saliva binds thaumatin nonspecifically. Tongues were cleansed by rinsing with an "artificial saliva," a solution containing a balanced mix of the electrolytes of saliva without the organic components (Hellekant et al., 1985). The posterior tongue in the foliate and/or vallate papilla region was treated with $0.3 \mathrm{M}$ sucrose or $33-40 \mathrm{mg} /$ litcr thaumatin (in artificial saliva) for 5-10 min and rinsed briefly with the electrolyte solution, and the foliate and/or vallate papillae were removed surgically. Control papillae were biopsied after rinsing with artificial saliva and were not treated with a sweetener. The monkeys were allowed to recover from anesthesia. The biopsy wounds were small and required no suture. Wounds healed within a few days, and there was little indication of discomfort or alteration in feeding habits. Specimens from 2-5 monkeys were used in each treatment group.

The specimens were fixed for $2 \mathrm{hr}$ in a modified Karnovsky's solution (Karnovsky, 1965) containing 2\% paraformaldehyde and 2\% glutaraldehyde in $0.1 \mathrm{M}$ cacodylate buffer, $\mathrm{pH} 7.2-7.4$. Tissues were then postfixed in $1 \% \mathrm{OsO}_{4}$ (cacodylate huffered) for $2 \mathrm{hr}$, dehydrated in an ascending series of ethanols, placed in propylene oxide, and embedded in epon-araldite (Luft, 1961). Thin sections of the taste bud-bearing regions of the foliate and vallate papillae were examined with the electron microscope (JEOL 100-CX), with particular attention to the taste pores. At least 2 or 3 sections of each pore were examined. A minimum of 5 or more small (50-100 $\mathrm{nm}$ ) vesicles in any pore was the basis for defining a vesicle-containing pore. The $\chi$-square test was used to determine whether significant differences occurred between control and experimental groups.

Neurophysiology. The initial anesthesia was the same as above, but the anesthesia was maintained by administrations of pentobarbital through a cannula in a radial vein. Surgery was performed under clean conditions.

The glossopharyngeal nerve was exposed caudal to the submandibular salivary gland and hyoid bone, medial to the digastric muscle, and rostral to the bifurcation of the common carotid artery. The nerve forms a single bundle at this point and is readily available for recording.

The overall nerve impulse activity was recorded with a PAR 113 amplifier, monitored over a loudspeaker and an oscilloscope, and fed into a recorder (Gould ES 1000) together with the output from an absolute value circuit integrator with a time constant of $100 \mathrm{msec}$ and a binary coded signal, which indicated the type of stimulus used as well as stimulation time. In addition, an IBM PC-AT with a DAS-Keithley interface was used for sampling individual responses.

Stimulation. The surface of the tongue was stimulated with a system that delivers solutions at programmed intervals and over a predetermined time under conditions of constant flow and temperature (Brouwer

\begin{tabular}{|c|c|c|c|c|}
\hline & $\begin{array}{l}\text { Number } \\
\text { of pores } \\
\text { with } \\
\text { vesicles }\end{array}$ & $\begin{array}{l}\text { Total } \\
\text { pores }\end{array}$ & $\%$ & Significance \\
\hline \multicolumn{5}{|l|}{ Foliate } \\
\hline Untreated (4) ${ }^{\alpha}$ & 21 & 30 & 70 & - \\
\hline Sucrose (3) & 14 & 21 & 67 & NS \\
\hline Thaumatin (5) & 33 & 36 & 92 & $p<0.02$ \\
\hline \multicolumn{5}{|l|}{ Vallate } \\
\hline Untreated (2) & 1 & 21 & 5 & - \\
\hline Sucrose (2) & 0 & 9 & 0 & NS \\
\hline Thaumatin (3) & 14 & 24 & 58 & $p \ll 0.0005$ \\
\hline
\end{tabular}

${ }^{a}$ The number in parentheses indicates the number of animals in each group.

et al., 1983). Each stimulation lasted for $10 \mathrm{sec}$, followed by a rinse interval of 30 or $50 \mathrm{sec}$ before the next stimulus was presented. The following solutions were used as stimuli: $0.02 \mathrm{~m}$ citric acid, $0.1 \mathrm{M} \mathrm{NaCl}$, $0.3 \mathrm{~m}$ sucrose, and $33-40 \mathrm{mg} /$ liter thaumatin. All solutions were made up in artificial saliva (Hellekant et al., 1985), which was also used to rinse the tongue between stimuli.

When the experiment was completed, the wound was sutured and the monkeys were returned to the postoperative care facility of the Wisconsin Regional Primate Center, where their recovery from anesthesia was monitored. Medications for pain or discomfort were administered if the need was apparent to the staff veterinarian. No infections occurred in any of the animals used in the physiological experiments.

\section{Results}

\section{Morphology}

In control, unstimulated taste buds, small vesicles, 50-100 nm diameter, were found in about $70 \%$ of pores from foliate papilla taste buds (Fig. 1a. Table 1). The 30 untreated foliate papilla taste pores included in these data came from 4 different animals, and within each batch the percentages containing vesicles varied from 40 to $100 \%$. We saw only one vesicle-containing pore from 21 vallate taste buds taken from 2 control animals (Fig. $1 b$ ).

In both types of papillae, stimulation with sucrose had no apparent effect on the frequency of occurrence of apocrine secretions. However, when thaumatin was used as a stimulus, there was a significant increase in the percentage of pores containing vesicles to $92 \%$ in foliate papillae $\left(\chi^{2}=8.04, d f=2, p\right.$ $<0.02)$ and $58 \%$ in vallate papillae $\left(\chi^{2}=143.7, d f=2, p \ll\right.$ 0.0005 ; Table 1).

\section{Neurophysiology}

Recordings were obtained from glossopharyngeal nerves in 4 monkeys. A typical sequence of responses to stimuli is seen in the tracings of Figure 2.

Of the 4 stimuli used in these experiments, response patterns to $\mathrm{NaCl}$, citric acid, and sucrose were similar to one another in the sense that they remained stable after several successive stimulations with the same tastant. However, after repeated stimulation with thaumatin, the response amplitude became smaller with each successive stimulus (adaptation). The last thaumatin stimulation in the sequence of 4 elicited a response with an amplitude $20-30 \%$ less than that elicited by the first (Figs. 2, 3). A curve fit of all data gave the equation: $\log (y)=4.19-$ $0.154 x+0.017 x^{2}$. A straight line connecting the data points has a statistically significant negative slope verifying the previously mentioned decrease of thaumatin response with repeated thaumatin stimulations. 

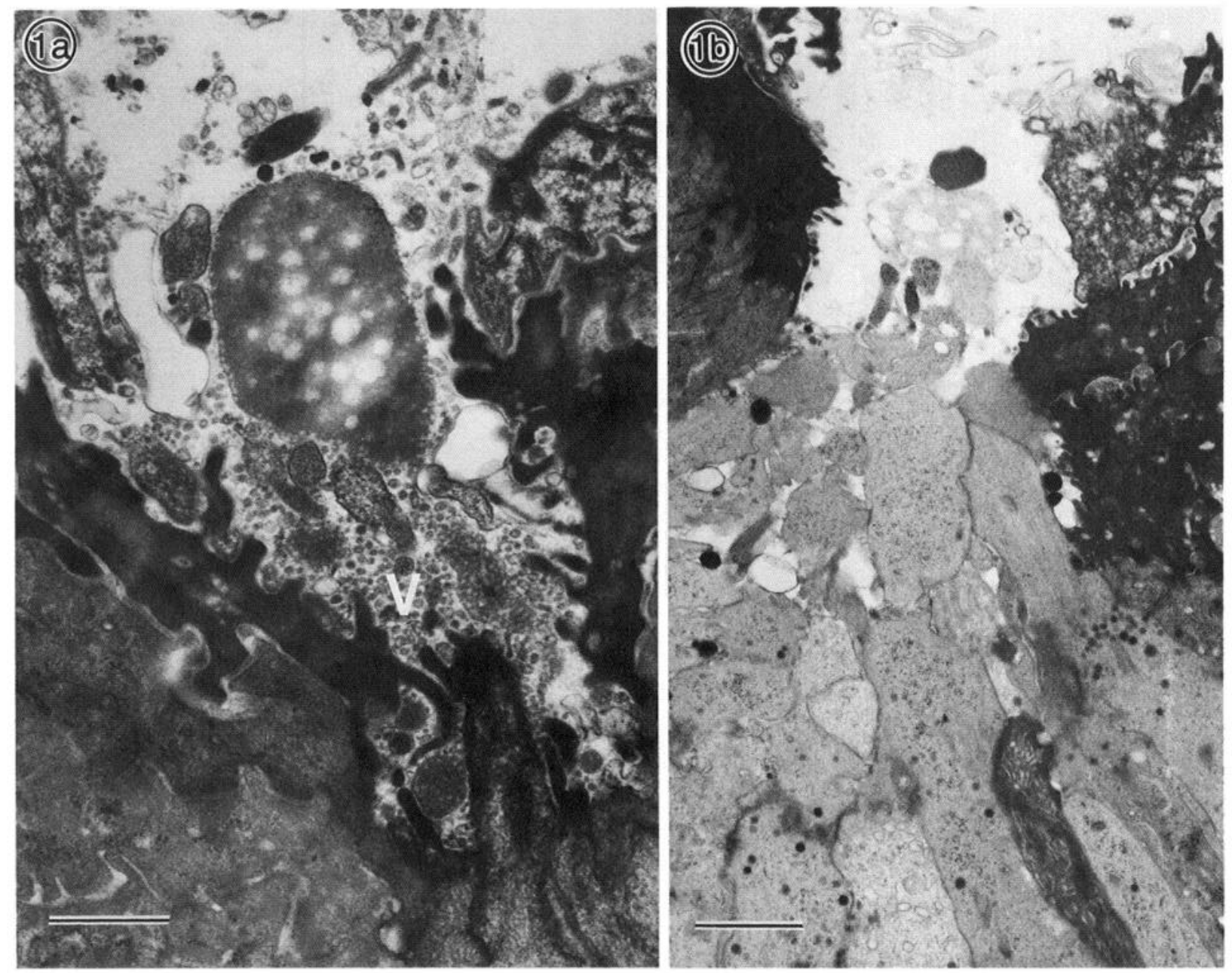

Figure 1. a, Electron micrograph of the pore region of an unstimulated taste bud from a foliate papilla. Large numbers of small vesicles (v) are seen within the pore. Scale bar, $1.0 \mu \mathrm{m}$. $b$, Electron micrograph of the pore region of an unstimulated taste bud from a vallate papilla. This pore contains no evidence of small vesicles, such as those seen in $a$. Scale bar, $1.0 \mu \mathrm{m}$.

Because presentation of repeated thaumatin stimuli resulted in a reduction of response amplitude to thaumatin itself, it was of interest to determine whether there was cross-adaptation between thaumatin and other stimuli. Prior stimulation with thaumatin had no cross-adaptive effect on a response to citric acid, i.e., the response amplitude to citric acid remained essentially unchanged (Fig. 4). Significant effects on $\mathrm{NaCl}$ responses could not be verified (data not shown).

However, the effect of 4 successive thaumatin stimulations caused reduction in the amplitude of the sucrose responses in the glossopharyngeal nerve (Fig. 5). A sequence of sucrose stimuli, alternating with thaumatin, was given, separated by $30-\mathrm{sec}$ rinses. Figure 5 shows that the sucrose response amplitude decreases after the first thaumatin stimulation and drops even further after the third. The amplitude of the response to sucrose recovered after thaumatin stimulation was discontinued for a few minutes. If $\mathrm{NaCl}$ and citric acid (not shown) were used as stimuli during the recovery period, they did not interfere with the recovery. The same effects were repeated during a second thaumatin-sucrose sequence, i.e., there was an evident decline in sucrose response amplitude. $\mathrm{NaCl}$ and citric acid responses were stable throughout this period and are not included in Figure 5.
It is particularly interesting to note that when the rinse interval between alternating thaumatin and sucrose stimuli was increased from $30 \mathrm{sec}$ to 1-2 min, no cross-adaptive effect was demonstrable (Fig. 6). In other words, when the taste buds were allowed a longer rest period between the stimuli, the response amplitude to a sucrose stimulus was not demonstrably different from what it had been before the thaumatin stimulus.

\section{Discussion}

A novel hypothesis

We found that after in vivo stimulation by thaumatin, a greater proportion of taste pores in both foliate and vallate papillae contains vesicles. At least some of the vesicles presumably arise from type II cells (Farbman et al., 1987). When sucrose was used as a stimulus, there was no significant change in the proportion of pores with vesicles. This indicated that thaumatin elicits shedding of the vesicles from microvilli, but sucrose does not.

The data are consistent with the following: (1) thaumatin is not handled by the cell simply by adsorption and desorption, as is probably the case with, e.g., sucrose (cf. Beidler, 1954), (2) the cell responds to a thaumatin stimulus by shedding membrane; the lost membrane may contain the stimulus-binding site 
Rh 85030880127 (Glosso)
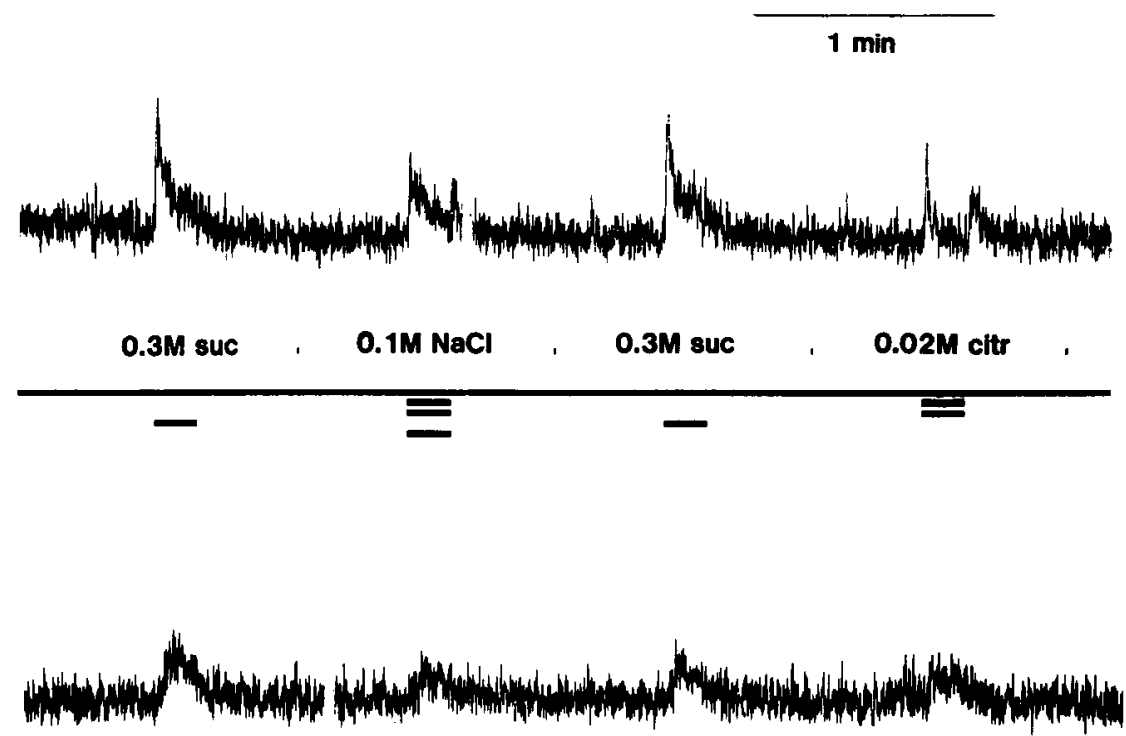

. thau $33 \mathrm{mg} / \mathrm{l}$. thau $33 \mathrm{mg} / 1$, theu $33 \mathrm{mg} / \mathrm{l}$, thau $33 \mathrm{mg} / 1$.
Figure 2. Part of a summated nerve recording to demonstrate how the standard ( $\mathrm{NaCl}$, citric acid, and sucrose) and the thaumatin stimulations were done to obtain the results shown in the following graphs. Part of one sequence of the 4 stimulation cycles is shown. A series of "standard" stimuli was applied before 4 consecutive stimulations with thaumatin. (This was repeated 4 times.) The figure shows some but not all the standard stimuli applied between the 4 thaumatin stimulations. complex, and (3) the consequence of shedding the membraneenclosed vesicles from the microvilli is a depletion of stimulus binding sites or a compromise in the functional integrity of the sweet receptor. The result, in either case, is a diminished neural response to thaumatin after repeated stimulation until a new steady state is reached. It is conceivable that this steady state is the result of a balance between rate of loss and rate of restoration of membrane receptors.

The prevailing ideas of sugar taste reception recently have been summarized by Jakinovich and Sugarman (1988), who modified Beidler's original equation (1954) to take into account the effect of competitive inhibition and adaptation. All models (Shallenberger and Acree, 1967; Hellekant, 1975; Faurion et al., 1980; Crosby and DuBois, 1981; Jakinovich, 1982; Yamada et al., 1983; Ninomiya et al., 1984; Beidler and Tonosaka, 1985; Van der Wel et al., 1987) assume that sweet taste is a result of weak adsorption of stimulus to the receptor on the taste cell membrane and that the stimulus is readily released from its receptor.

Our data in this and our previous paper (Farbman et al., 1987)

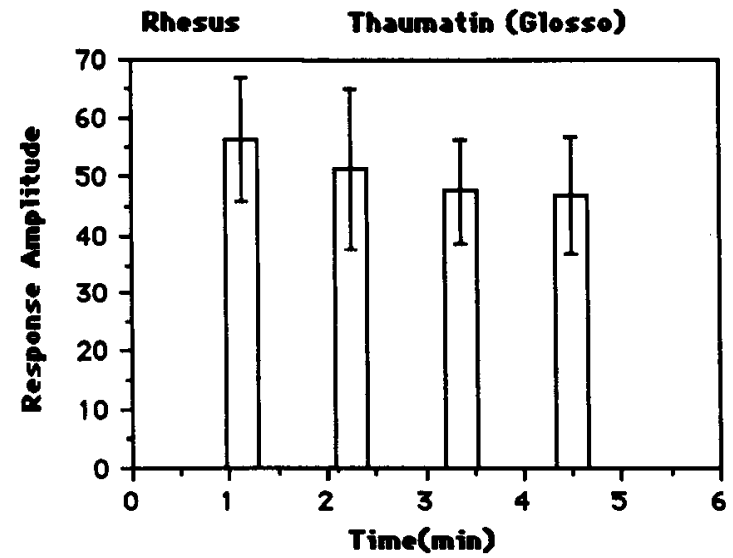

Figure 3. The average amplitude of the responses to thaumatin in all animals has been plotted as bars. Thaumatin was applied in 4 consecutive stimulations with a $50-\mathrm{sec}$ rinsing period between stimulations. The graph shows the strong adaptive effect thaumatin had on its own response; the response amplitude became smaller with each successive stimulus. The last thaumatin stimulation in the sequence of 4 elicited a response with an amplitude considerably less than that elicited by the first.

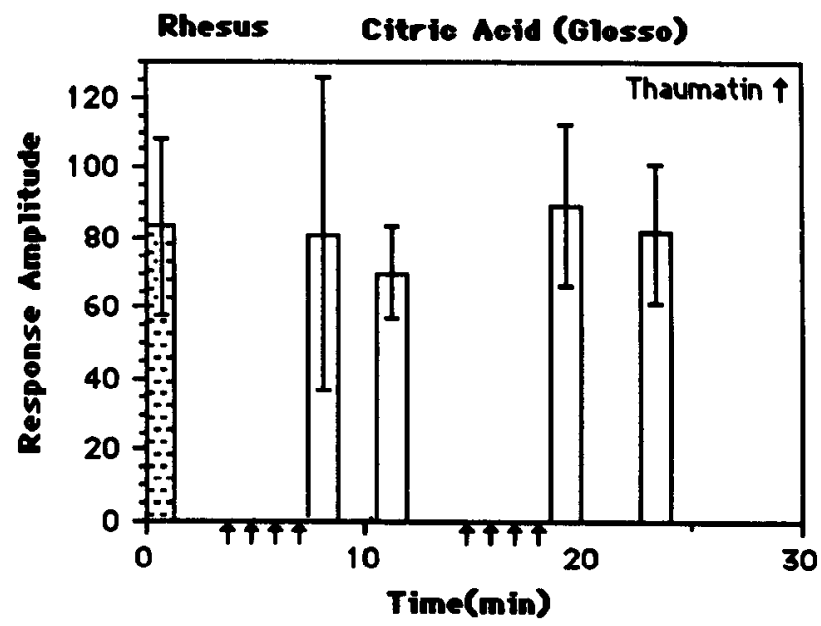

Figure 4. The times of thaumatin stimulations are indicated by the arrows below the $x$-axis. The dotted bar at the left represents the average response amplitude to citric acid stimuli from all animals before any thaumatin stimulation. Thaumatin had no significant cross-adaptive effect on citric acid. 


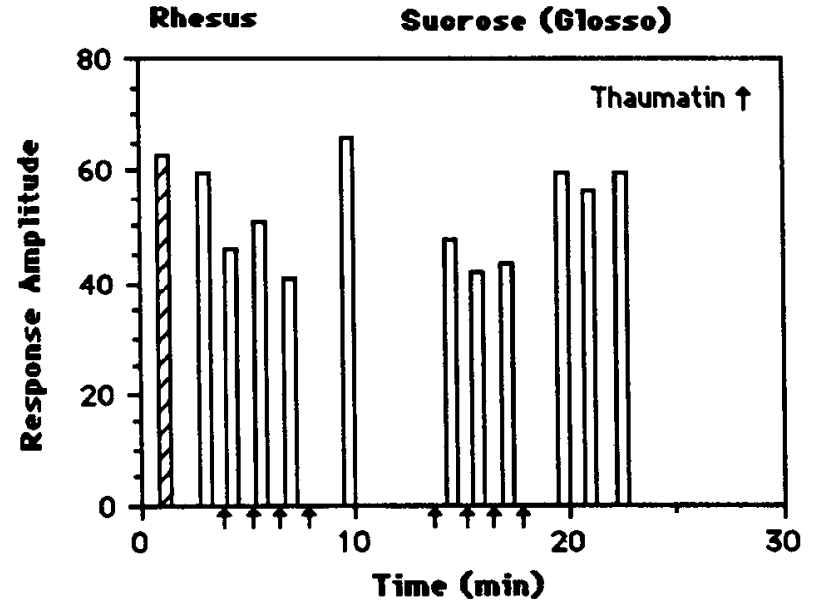

Figure 5. The response amplitudes of a sequence of sucrose and thaumatin stimulations at 30-sec intervals were plotted from one monkey. The thaumatin stimulations are illustrated by the arrows just below the $x$-axis. It is evident that thaumatin attenuated the response to sucrose at these intervals.

suggest that the mechanism by which the taste cell binds and releases thaumatin differs significantly from the weak adsorption-desorption mechanism described for other sweet stimuli. Several observations support this idea. First, repeated stimulation with thaumatin results in reduction of the response amplitude to successive stimuli. This does not happen after repeated stimulation with sucrose, $\mathrm{NaCl}$, or citric acid.

Second, prior stimulation with thaumatin attenuates the response to sucrose, but prior stimulation with sucrose does not reduce the response to thaumatin (Brouwer et al. 1973). Moreover, the reduction by thaumatin of responses to sucrose lasts considerably longer than the adaptation seen between other sweeteners. We believe that this phenomenon can be explained if there is more than one kind of sweet binding site (Hellekant, 1975; Faurion et al., 1980; Jakinovich, 1982; Yamada et al., 1983; Beidler and Tonosaka, 1985; Van der Wel et al., 1987; Jakinovich and Sugarman, 1988) and the binding sites-receptors for other sweeteners are physically close to those for thaumatin on the taste cell membrane. If this is true, when membranes containing thaumatin binding sites are altered or actually shed into the pore with the vesicles, the nearby binding sites for sucrose and other sweeteners also are compromised. As a consequence, other sweet binding sites-receptors are functionally altered or lost in the shed vesicles, and the cell becomes less responsive to the other sweeteners.

A third observation supporting our hypothesis that the mechanism by which taste cells handle thaumatin differs from that by which they handle sucrose is that stimulation with sucrose results in no increased shedding of membrane. This is consistent with the observation that the amplitude of the neural response to sucrose is essentially unchanged after repeated stimulation, and there is no cross-adaptive effect when sucrose is used as the first stimulus and thaumatin as the second.

It is not clear, at this point, if this process involves only receptors to sweet compounds. Some of our recordings indicate that the response to $\mathrm{NaCl}$ may also be decreased following a prior thaumatin stimulus, but for several reasons, the effects are more difficult to document. One reason is that the response to $\mathrm{NaCl}$ in the monkey is considerably smaller in the glossopharyn-

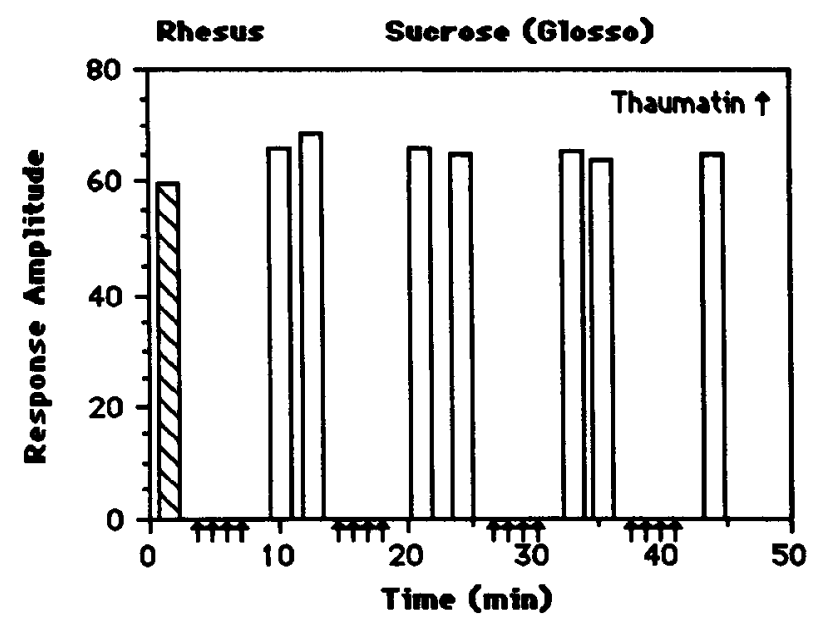

Figure 6. Similar to Figure 5 except that the rinse intervals between the thaumatin and sucrose stimuli were increased to more than $1 \mathrm{~min}$. Under these conditions, there was no suppression of sucrose response amplitude.

geal nerve than in the chorda tympani nerve. This means that there is a less favorable signal-to-noise ratio. Another reason is that the effects, even when the above is taken into account, are smaller. However, this uncertainty does not contradict the hypothesis suggested previously. It is very likely that ion channels participate in the taste response, and if shedding of cell membrane is part of the release mechanism for thaumatin, the shed membrane may contain ion channels as well.

\section{Taste pore vesicles}

Data on the proportion of vallate and foliate taste pores containing vesicles have not been reported in previous morphological studies (Murray, 1973; Farbman et al., 1985). In taste buds of fungiform papillae of rats (Farbman, 1965; Murray et al., 1972), mice (Mattern and Pavan, 1974), and rabbits (Murray et al., 1972; Murray, 1973), vesicles have been described, although little attention has been paid to their importance. It has been noted that fungiform papilla taste pores contained more vesicles than foliate papilla pores (Murray et al., 1972; Murray, 1973). There is probably a basal or equilibrium rate of vesicle shedding, reflecting membrane turnover, in taste pores from all three types of gustatory papillae in the tongue in the unstimulated condition. Based on our data from this study and on the data of others, we suggest that the basal rate of vesicle formation may be highest in fungiform papillae, next highest in foliate papillae, and lowest in vallate papillae. The fungiform taste buds might be more predisposed to a rapid basal rate of continual shedding because of their location on the anterior part of the tongue, where they are more exposed to potential physical and chemical trauma (Beidler, 1967). The taste buds on both the foliate and vallate papillae are more sheltered, by virtue of their location in crypts. It is not clcar, however, why there should be a major difference between vallate and foliate taste pores in the number of pores with vesicles in unperturbed animals.

Although the reasons for the differences in basal rates of vesicle shedding are not really known, it is clear from our data that they can be modulated by stimulation, at least in the posterior part of the tongue. It is possible that continued renewal of membrane in the stimulus binding region of taste cells serves several functions, perhaps replacement of "worn out" receptor or trans- 
duction molecules or ion channels. In any case, the continued shedding of microvillar membrane, even in the unstimulated taste pore, imposes on the cell the constant need to replace lost membrane and lost receptors.

\section{Vesicle loss by other cell types}

Shedding of vesicles or blebs is a well-known phenomenon that occurs under normal and experimental conditions in many cell types. In the photoreceptor of the retina, the distal portion of the outer segment (including the receptor component, namely, the rhodopsin-containing disks) is continually shed and phagocytosed by pigment epithelial cells. The lost cytoplasm is continually replaced by new synthesis of membrane and cytoplasm components in the inner segment (Young, 1967; Young and Bok, 1969; Hall, 1978). In murine lymphocytes, shedding of transmembrane integral proteins occurs in association with membrane lipid as tiny vesicles, but not all membrane molecules are shed at the same rate (Emerson and Cone, 1981).

In culturcd cclls, such as Chinese hamster ovary cells, blebbing or vesiculation of membranes has been observed during mitosis (Prothero and Spencer, 1968; Porter et al., 1973). Moreover, exfoliation of membrane ectoenzymes in the form of microvesicles is known to occur in cultures of normal and neoplastic cell lines even when they are not dividing (Trams et al., 1981). Release of blebs or vesicles by cultured cells can occur in response to cold (Liepjins and Hillman, 1981), agents that increase cytosolic $\mathrm{Ca}^{2+}$ (Nicotera et al., 1986), very low (10-25 mM) concentrations of formaldehyde and other agents that induce cell injury (Hoerl and Scott, 1978; Scott et al., 1979), and other stimulants. In the morphological part of the present study, we exposed all taste bud specimens to the same concentrations of aldehyde fixative, yet there were clear differences in the proportion of vesicle containing taste pores between the thaumatintreated tissue and untreated or sucrose-treated tissue. Therefore, it is highly unlikely that the vesicle formation in taste buds was due to aldehyde treatment.

\section{Thaumatin-binding protein}

A thaumatin-binding protein has recently been identified in preparations of monkey vallate papillae. The protein has a $M_{\mathrm{r}}$ of approximately 50,000 daltons, as determined by polyacrylamide gel electrophoresis, and binds to thaumatin but not to acetylated thaumatin, which does not taste sweet (Shimazaki et al., 1985, 1986; Sato, 1987). Regions of the tongue that contain no taste buds do not contain this protein. On the basis of its solubility in borate buffer without detergents, we suggest that the binding protein is easily releasable from the membrane. Our data suggest the possibility that the ease with which the binding protein is releasable from the membrane might be explained by the shedding phenomenon. Perhaps the tiny pore vesicles are not captured by centrifugation in the membranc fraction of the homogenized tissue.

\section{Conclusion}

The results support the suggestion that the thaumatin-binding sites on the taste microvillar membrane bind thaumatin tightly and are shed as a stimulus-binding site complex into the pore or are functionally altered as a result of membrane loss. Prior stimulation with thaumatin alters the response to sucrose, possibly because the sucrose receptor is located close to that for thaumatin. The compromise in functional activity of the thau- matin receptors imposes on the cell the need to restore the equilibrium to the resting state.

\section{References}

Beidler, L. M. (1954) A theory of taste stimulation. J. Gen. Physiol. 38: 133-139.

Beidler, L. M. (1967) Anion influences on taste receptor response. In Olfaction and Taste 2, T. Hayashi, ed., pp. 509-534, Pergamon, Oxford.

Beidler, L. M., and K. Tonosaka (1985) Multiple sweet receptor sites and taste theory. In Taste, Olfaction and the Central Nervous System, A Festschrift in Honor of Carl Pfaffmann, D. Pfaff, ed., pp. 47-64, Rockefeller U. P., New York.

Brouwer, J. N., G. Hellekant, Y. Kasahara, H. Van der Wel, and Y. Zotterman (1973) Electrophysiological study of the gustatory effects of the sweet proteins monellin and thaumatin in monkey, guinea pig and rat. Acta Physiol. Scand. 89: 550-557.

Brouwer, J. N., D. Glaser, C. Hàrd af Segerstad, G. Hellekant, Y. Ninomiya, and $H$. van der Wel (1983) The sweetness-inducing effect of miraculin: Behavioural and neurophysiological experiments in the rhesus monkey (Macaca mulatta). J. Physiol. (Lond.). 337: 221-240.

Crosby, G. A., and G. E. DuBois (1981) Sweeteners and receptor sites. In Towards Understanding Receptors, J. W. Lamble, ed., pp. 223229, Elsevier/North-Holland, Amsterdam.

DeVos, A. M., M. Hatada, H. Van der Wel, H. Krabbendam, A. F. Peerdeman, and S. H. Kim (1985) Three-dimensional structure of thaumatin I, an intensely sweet protein. Proc. Natl. Acad. Sci. USA 82: 1406-1409.

Emerson, S. G., and R. E. Cone (1981) I-K $\mathrm{K}^{k}$ and $\mathrm{H}-2 \mathrm{~K}^{\mathrm{k}}$ antigens are shed as supramolecular particles in association with membrane lipids. J. Immunol. 127: 482-486.

Farbman, A. I. (1965) Fine structure of the taste bud. J. Ultrastruct. Res. 12: 328-350.

Farbman, A. I., G. Hellekant, and A. Nelson (1985) Structure of taste buds in foliate papillae of the Rhesus monkey, Macaca mulatta. Am. J. Anat. 172: 41-56.

Farbman, A. I., C. K. Ogden-Ogle, G. Hellekant, S. R. Simmons, R. M. Albrecht, and H. Van der Wel (1987) Labeling of sweet tastebinding sites using a colloidal gold-labeled sweet protein, thaumatin. Scan. Microsc. 1: 351-357.

Faurion, A., S. Saito, and P. MacLeod (1980) Sweet taste involves several distinct receptor mechanisms. Chem. Senses 3: 107-121.

Glaser, D., G. Hellekant, J. N. Brouwer, and H. Van der Wel (1978) The taste responses in primates to the proteins thaumatin and monellin and their phylogenetic implications. Folia Primatol. (Basel) 29: $56-63$.

Hall, M. O. (1978) Phagocytosis of light- and dark-adapted rod outer segments by cultured pigment epithelium. Science 202: 526-528.

Hellekant, G. (1975) Different types of sweet receptors in mammals. In Olfaction and Taste V, D. A. Denton and J. P. Coghlan, eds., pp. 15-21, Academic, New York.

Hellekant, G. (1976) On the gustatory effects of monellin and thaumatin in dog, hamster, pig and rabbit. Chem. Senses Flavour 2: 97105.

Hellekant, G., C. Hàrd af Segerstad, T. Roberts, H. Van der Wel, J. N. Brouwer, D. Glaser, R. J. Hayes, and J. W. Eichberg (1985) Effects of gymnemic acid on the chorda tympani proper nerve responses to sweet, sour, salty and bitter taste stimuli in chimpanzee. Acta Physiol. Scand. 124:399-408.

Hoerl, B. J., and R. E. Scott (1978) Plasma membrane vesiculation: A cellular response to injury. Virchows Arch. [Cell Pathol.] 27: 335345.

Iyengar, B., P. Smits, F. Van der Ouderaa, H. Van der Wel, J. Van Brouweshaven, P. Ravstein, G. Richters, and P. D. Van Wassenaar (1979) The complete amino acid sequence of the sweet protein thaumatin I. Eur. J. Biochem. 96: 193-204.

Jakinovich, W., Jr. (1982) Stimulation of the gerbil's gustatory receptors by saccharin. J. Neurosci. 2: 49-56.

Jakinovich, W., Jr., and D. Sugarman (1988) Sugar taste reception in mammals. Chem. Senses 13: 13-31.

Karnovsky, M. J. (1965) A formaldehyde-glutaraldehyde fixative of high osmolality for use in electron microscopy. J. Cell Biol. 27:137A.

Liepjins, A., and A. J. Hillman (1981) Shedding of tumor cell surface membranes. Cell Biol. Int. Rep. 5: 15-26. 
Luft, J. H. (1961) Improvements in epoxy resin embedding methods. J. Biophys. Biochem. Cytol. 9: 409-414.

Mattern, C. F. T., and N. Pavan (1974) Evidence of a contractile mechanism in the taste bud of the mouse fungiform papilla. Exp. Neurol. 44: 461-469.

Murray, R. G. (1973) The ultrastructure of taste buds. In The Ultrastructure of Sensory Organs, I. Friedmann, ed., pp. 1-81, NorthHolland, Amsterdam.

Murray, R. G., A. Murray, and G. Hellekant (1972) Fine structure of taste buds of rat fungiform papillae. In Olfaction and Taste IV, Proceedings of the Fourth Symposium, D. Schneider, ed., pp. 56-62, Wissenschaftliche Verlagsgesellschaft, Stuttgart.

Nicotera, P., P. Hartzell, G. Davis, and S. Orrenius (1986) The formation of plasma membrane blebs in hepatocytes exposed to agents that increase cytosolic $\mathrm{Ca}^{2+}$ is mediated by the activation of a nonlysosomal proteolytic system. FEBS Lett. 209: 139-144.

Ninomiya, Y., T. Higashi, H. Katsukawa, T. Mizukoshi, and M. Funakoshi (1984) Qualitative discrimination of gustatory stimuli in three different strains of mice. Brain Res. 322: 83-92.

Porter, K., D. Prescott, and J. Frye (1973) Changes in surface morphology of Chinese hamster ovary cells during the cell cycle. J. Cell Biol. 57: 815-836.

Prothero, J. W., and D. Spencer (1968) A model of blebbing in mitotic tissue culture cells. Biophys. J. 8: 41-51.

Sato, M. (1987) Taste receptor proteins. Chem. Senses 12: 277-283.

Scott, R. E., R. G. Perkins, M. A. Zschunke, B. J. Hoerl, and P. B. Maercklein (1979) Plasma membrane vesiculation in 3T3 and SV3T3 cells. I. Morphological and biochemical characterization. J. Cell Sci. 35: 229-243.

Shallenberger, R. S., and T. E. Acree (1967) Molecular theory of sweet taste. Nature 216:480-482.
Shimazaki, K., M. Sato, and M. Nakao (1985) Thaumatin-binding protein in monkey circumvallate papillae. In Proceedings of the 19th Japanese Symposium on Taste and Smell, S. Kimura, A. Miyoshi, and I. Shimada, eds., pp. 173-176, Japancse Association for the Study of Taste and Smell, Tokyo.

Shimazaki, K., M. Sato, and M. Nakao (1986) Photoaffinity labeling of thaumatin-binding protein in monkey circumvallate papillae. Biochim. Biophys. Acta 884: 291-298.

Trams, E. G., C. J. Lauter, N. Salem Jr., and U. Heine (1981) Exfoliation of membrane ecto-enzymes in the form of micro-vesicles. Biochim. Biophys. Acta 645: 63-70.

Van der Wel, H., and W. J. Bel (1976) Effect of acetylation and methylation on the sweetness intensity of thaumatin I. Chem. Senses Flavour 2: 211-218.

Van der Wel, H., and K. Loewe (1972) Isolation and characterization of thaumatin I and II, the sweet-tasting proteins from Thaumatococcus danielli Benth. Eur. J. Biochem. 31: 221-225.

Van der Wel, H., A. Van der Heijden, and H. G. Pecr (1987) Sweeteners. Food Rev. Int. 3: 193-268.

Yamada, H., T. Imito, and Y. Hiji (1983) Discrimination of molecular structure of various sugars in the sweet receptor sites of the rat tongue. In Proceedings of the Japanese Symposium on Taste and Smell XVII, pp. 33-36, Japanese Association for the Study of Taste and Smell, Tokyo.

Young, R. W. (1967) The renewal of photoreceptor cell outer segments. J. Cell Biol. 33: 61-72.

Young, R. W., and D. Bok (1969) Participation of the retinal pigment epithelium in the rod outer segment renewal process. J. Cell Biol. 42: $392-403$. 